\section{Gender and side effects of group cognitive behavior psychotherapy}

\author{
Michael Linden ${ }^{1 *}$, Beate Muschalla ${ }^{2}$ and Mara Walter ${ }^{1}$ \\ ${ }^{1}$ Research Group Psychosomatic Rehabilitation, Charité University, Medicine Berlin, Berlin, Germany \\ ${ }^{2}$ Department of Psychology, University of Braunschweig, Braunschweig, Germany
}

\section{Abstract}

Males and females are different in their interactional behavior, their way of suffering, and their way of expressing themselves. It is therefore supposed that they react differently in group settings. This includes the degree to which they experience burdens and side effects of group psychotherapy. The objective of the study was to explore side effects of group psychotherapy in relation to gender. Seventy one patients in cognitive behavioral group psychotherapy were assessed with the UE G scale (unwanted events in groups). Burdens or side effects were reported by $98.6 \%$ of patients, severe and extremely severe burdens by $43.7 \%$ of patients. The highest average scores were found for "I was afraid not to know how to proceed in the future $(1,34)$ ", "I realized how complicated everything is $(1,32)$ ", "I have experienced the ongoing group therapy as burdensome $(1,29)$ ", and "I have learned that group therapy is not my thing $(1,01)$ ". Males score higher in their global judgement that group therapy was burdensome. There were no further significant differences in any of the specific items. The data suggest that side effects are a regular companion of group psychotherapy. A major negative effect of group psychotherapy is demoralization because of the observation of other patients, their problems and problem explanations. This is the same for both sexes. Research is needed on how to minimize burdens for patients.

\section{More Information}

*Address for Correspondence: Michael Linden Research Group Psychosomatic Rehabilitation, Charité University, Medicine Berlin, Berlin, Germany, Tel: +49 30170 5325697;

Fax: (030) 8445-4048;

Email: michael.linden@charite.de

Submitted: 19 March 2020

Approved: 30 March 2020

Published: 31 March 2020

How to cite this article: Linden M, Muschalla B, Walter M. Gender and side effects of group cognitive behavior psychotherapy. Arch Psychiatr Ment Health. 2020; 4: 014-018.

DOI: 10.29328/journal.apmh.1001012

Copyright: @ 2020 Linden M, et al. This is an open access article distributed under the Creative Commons Attribution License, which permits unrestricted use, distribution, and reproduction in any medium, provided the original work is properly cited.

Check for updates

OPEN ACCESS

\section{Introduction}

There are many research results suggesting major differences between sexes in regard to the prevalence of mental disorders, the openness to report about problems and insufficiencies, and the utilization of treatment $[1,2]$. The same life events or demands can have different impacts on men and women [3]. Women use a more emotional way of speaking, whereas men often tend to suppress emotional reactions $[4,5]$. These gender differences have a direct relevance to psychotherapy in general and to group psychotherapy in particular [6-12]. The different ways of expressing oneself, of emotional reactions, and admitting weakness should be intensified in group settings, especially in groups with participants of both sexes [13]. Considering that men think they have to be strong and dominant, it can offend their self-esteem if they have to show fear and weakness in front of a group. Women interact less hierarchically in women-only groups, which can result in problems in mixed gender groups [14]. Even if there is no final consensus on different ways of communication styles between men and women, there is a need of gender-related research. The efficacy of psychotherapy could be increased by adaption to gender, and psychotherapy outcome research must consider gender aspects $[3,15,16]$.
This is also true for side effects of psychotherapy. Side Effects (SE) are unwanted events (UE), which are adverse treatment reactions (ATR) because they have been caused by a therapeutic intervention, and which have been applied according to professional standards $[17,18]$. SE shall be delineated from UE which are unrelated to treatment, like most cases of nonresponse, or from adverse treatment reactions (ATR) which are due to malpractice. Side effects occur in all types of psychotherapy on a regular basis [19-21].

Group psychotherapy is in general especially prone to generate side effects, due to complex group processes. Because of patient-patient interactions there is the possibility of mutual aggression, dominance, or bullying, which can be difficult for the therapist to control [22-24]. Furthermore, patients observe each other, listen to communications and can get the wrong message, be negatively impressed by the suffering of others, or be demoralized by the complexities or possible negative courses of mental illness $[25,26]$. The assumption is that both sexes react differently in groups, and that especially males have difficulties with psychotherapy groups and should report more burdens.

The present study is to our knowledge the first to explore 
differences in regard to burdens and side effects of group cognitive behavior therapy in relation to both sexes.

\section{Method}

\section{Patients}

The study was carried out in a psychosomatic hospital and approved by the internal review board and directorate of the institution. Patients were treated as inpatients for about five weeks, with two sessions of individual and two of group psychotherapy per week, sociotherapy, ergotherapy, sport therapy, and medical treatment and pharmacotherapy as needed.

Participants were a convenience sample of 71 patients. Their age was on average 49.7 (SD $=8.7$ ) years, $50.7 \%$ had a high-school degree. They were suffering from depressive, anxiety, somatization, or personality disorders. Sixty-two percent were on sickness absence and $45.5 \%$ had already participated in group psychotherapy before.

\section{Treatment}

Group psychotherapists were ten therapists, 8 female, with an average age of 37.1 (SD $=6.9$ ) years, a state-licensed training in cognitive behavior therapy and 7.38 (SD = 7.85) years of postgraduate experience. Group contents were problem-solving, social competency, coping with anxiety, depression, and somatization.

Treatment strategies were analysis and modification of psychosomatic symptoms, dysfunctional cognitions, cue exposure, and behavior. The group setting helped to exchange experiences, discuss solutions, and give mutual support and reassurance. Patients had on average $5.8(\mathrm{SD}=3.9)$ sessions of group psychotherapy when they were interviewed.

\section{Instrument}

Patients filled in the UE-G scale [25]. It has 48 items (Table 1) which ask for burdens caused by the ongoing treatment regarding the size of the group and the room (8 items), burdens caused by the content of discussions ( 9 items), burdens caused by the behavior of other patients (8 items), caused by behavior of the therapist (8 items), anticipated long-term effects of the group treatment (9 items), and global judgment of group burdens (4 items), and to which degree the group therapy was experienced as helpful or burdensome (2 items). Answers are given on a five-point Likert scale from $0=$ no problem to $4=$ extremely burdensome. The interpretation of the scale is different from other selfrating scales which measure psychological dimensions. Side effects are single events and each side effect stands for itself. We therefore count the number of side effects and report averages of sums.

\section{Results}

Burdens and side effects were reported by $98.6 \%$ of patients. If one takes into account only ratings of 3 and 4 , which means severe and extremely severe burdens, there are still $43.7 \%$ of patients who report at least one of such side effects. These side effects were reported in regard to all sub dimensions of the UE-G scale. The highest average scores were found for "I was afraid not to know how to proceed in the future" $(1,34)$, "I realized how complicated everything is" $(1,32)$ and "I have experienced the ongoing group therapy as burdensome" $(1,29)$, and "I have learned that group therapy is not my thing" $(1,01)$.

Table 1 displays the results for males and females. Males score higher in their global judgment that in general the group therapy was burdensome. There were no further differences in any of the specific items.

\section{Discussion}

A first result of our study is that burdens and side effects are a regular companion of group psychotherapy since almost all patients complain about at least one burden or every second patient about severe burdens. It has been known for a long time that group psychotherapy is not only effective but also bears risks for unwanted effects $[22,23,27,28]$. The same processes may be helpful or detrimental. Interaction with other patients or the therapist and the observation of their problems can relieve the patients of the pressure they are experiencing, but can also be a burden [29,30]. Items with the highest degree of approval indicate that listening to the discussion and observing other patients resulted in a feeling that one might be sicker than assumed in advance, that everything is very complicated and in insecurity in regard to the future. This can be summarized as demoralization. Despair of other participants can infect some of the patients and trigger own traumatic experiences, resulting in a deterioration of the emotional feelings instead of relieving the pressure [23].

In light of the literature on gender differences in general and in psychotherapy in particular, including the stereotype that men have to be strong, non-emotional and dominant, whereas females are allowed to be emotional and even to cry, relate empathically to others, and communicate easily [13], the hypothesis has been that males and females react differently to group psychotherapy where patients are prompted to speak about their emotions and their insufficiencies, where they must interact with other persons, talk, fit into hierarchical group dynamics, and also watch other persons who speak about their illness and problems. The assumption is that males have greater problems, since there is some evidence that they need more help in psychotherapy than women in speaking about their feelings in general, that it is more offending for them to present their feelings in front of a group, and that they have a tendency to rather suppress their feelings in social situations [3,4].

This hypothesis is somewhat supported, as males make a more negative global judgement about their group 
Table 1: Comparisons of male and female patients concerning self-reported side effects of group psychotherapy

\begin{tabular}{|c|c|c|c|c|}
\hline & All $(N=71)$ & $f(n=41)$ & $\mathrm{m}(n=30)$ & Significance of group differences in $t$ - test. \\
\hline I have experienced the ongoing group therapy as helpful & $1.86(1.13)$ & $1.76(1.28)$ & $2.00(0.87)$ & -0.96 \\
\hline I have experienced the ongoing group therapy as burdensome & $1.29(1.12)$ & $1.54(1.14)$ & $0.97(1.02)$ & $2.14^{*}$ \\
\hline \multicolumn{5}{|l|}{ When thinking about the size of the group and/or the room... } \\
\hline I feel cramped & $0.46(0.84)$ & $0.56(0.92)$ & $0.33(0.71)$ & 1.13 \\
\hline My absence would not have been noticed & $0.35(0.59)$ & $0.33(0.53)$ & $0.38(0.68)$ & -0.38 \\
\hline I felt under observation and/or at the mercy of others & $0.52(0.77)$ & $0.54(0.78)$ & $0.50(0.77)$ & 0.20 \\
\hline I felt lost & $0.31(0.65)$ & $0.27(0.55)$ & $0.37(0.77)$ & -0.63 \\
\hline I felt anxious or had a feeling of constriction & $0.70(0.93)$ & $0.78(1.06)$ & $0.60(0.72)$ & 0.85 \\
\hline I felt inhibited and shy to speak & $0.71(0.89)$ & $0.68(0.93)$ & $0.75(0.84)$ & -0.30 \\
\hline I felt in a goldfish bowl & $0.63(1.02)$ & $0.63(0.99)$ & $0.63(1.07)$ & 0.01 \\
\hline I felt uncomfortable close to the others & $0.49(0.91)$ & $0.54(0.87)$ & $0.43(0.97)$ & 0.47 \\
\hline \multicolumn{5}{|l|}{ When I think about the content of the group discussion... } \\
\hline I learned that there is nothing you can do about your problems & $0.79(1.01)$ & $0.75(1.03)$ & $0.83(0.99)$ & -0.34 \\
\hline I do not know what to think & $0.51(0.84)$ & $0.51(0.75)$ & $0.50(0.97)$ & 0.06 \\
\hline I could not see that my problem had been addressed & $0.88(1.20)$ & $0.90(1.14)$ & $0.87(1.28)$ & 0.11 \\
\hline I realized how complicated everything is & $1.32(1.13)$ & $1.44(1.07)$ & $1.17(1.21)$ & 1.00 \\
\hline I was afraid not to know how to proceed in the future & $1.34(1.29)$ & $1.41(1.41)$ & $1.23(1.10)$ & 0.61 \\
\hline I saw even more problems & $1.00(1.03)$ & $0.90(0.99)$ & $1.13(1.07)$ & -0.94 \\
\hline I felt worse than before & $0.90(1.23)$ & $0.95(1: 20)$ & $0.83(1.29)$ & 0.39 \\
\hline I am confused & $0.48(0.99)$ & $0: 44(1.07)$ & $0.53(0.90)$ & -0.40 \\
\hline I felt that I am too stupid to understand & $0.44(0.91)$ & $0.37(0.89)$ & $0.53(0.94)$ & -0.77 \\
\hline \multicolumn{5}{|l|}{ When I think about the other participants of the group } \\
\hline I had to tolerate criticism or insults & $0.11(0.58)$ & $0.05(0,32)$ & $0.20(0.81)$ & -0.97 \\
\hline I felt of no significance and/or worthless & $0.35(0.88)$ & $0.41(0.92)$ & $0.27(0.83)$ & 0.70 \\
\hline I felt that I was not part of to the group & $0.75(1.14)$ & $1.08(1.80)$ & $0.60(0.97)$ & 1.41 \\
\hline I felt obliged to speak & $0.39(0.73)$ & $0.24(0.58)$ & $0.60(0.86)$ & $-1.97^{\mathrm{a}}$ \\
\hline I felt under pressure & $0.56(1.05)$ & $0.39(0.77)$ & $0.80(1.30)$ & -1.52 \\
\hline I had no chance to speak & $0.08(0.33)$ & $0.07(0.26)$ & $0.10(0.40)$ & -0.34 \\
\hline I felt marginalized & $0.08(0.50)$ & $0.02(0.16)$ & $0.17(0.75)$ & -1.03 \\
\hline I felt that my problems are more severe than I thought before & $0.89(1.20)$ & $0.75(1.13)$ & $1.07(1.29)$ & -1.10 \\
\hline \multicolumn{5}{|l|}{ When I think about the therapist } \\
\hline I felt a tension between both of us & $0.10(0.46)$ & $0.00(0.00)$ & $0.23(0.68)$ & $-1.88^{b}$ \\
\hline I felt criticized and belittled & $0.08(0.37)$ & $0.07(0.35)$ & $0.10(0.40)$ & -0.30 \\
\hline I felt dominated and overrun & $0.08(0.37)$ & $0.05(0.31)$ & $0.13(0.43)$ & -0.96 \\
\hline I felt ignored & $0.06(0.29)$ & $0.02(0.16)$ & $0.10(0.40)$ & -0.98 \\
\hline I felt that he/she was not in control of the group & $0.13(0.45)$ & $0.12(0.49)$ & $0.13(0.43)$ & -0.11 \\
\hline I felt that the therapist is incompetent & $0.04(0.27)$ & $0.05(0.32)$ & $0.03(0.18)$ & 0.26 \\
\hline I think that the therapist is more sick than the patients & $0.00(0.00)$ & $0.00(0.00)$ & $0.00(0.00)$ & ${ }^{c}$ \\
\hline I had the feeling that he/she made fun of me & $0.04(0.27)$ & $0.02(0.16)$ & $0.07(0.37)$ & -0.69 \\
\hline \multicolumn{5}{|l|}{ After participating in the group ... } \\
\hline I am determined not to participate in further group sessions & $0.56(1.08)$ & $0.63(1.09)$ & $0.47(1.07)$ & 0.64 \\
\hline I am determined to be very cautious and taken back in future group session & $0.48(0.75)$ & $0.46(0.67)$ & $0.50(0.86)$ & -0.20 \\
\hline I am determined to express myself more clearly & $0.54(0.81)$ & $0.40(0.67)$ & $0.73(0.94)$ & -1.73 \\
\hline I feel worse than before & $0.70(1.05)$ & $0.73(1.06)$ & $0.67(1.06)$ & 0.28 \\
\hline I feel more apprehension and anxiety than before & $0.77(1.05)$ & $0.78(0.91)$ & $0.77(1.22)$ & 0.06 \\
\hline I do less dare to speak up than before & $0.15(0.55)$ & $0.07(0.26)$ & $0.27(0.79)$ & -1.30 \\
\hline I do less dare to approach other persons than before & $0.20(0.60)$ & $0.12(0.33)$ & $0.30(0.84)$ & -1.10 \\
\hline I have no longer trust in therapists & $0.08(0.50)$ & $0.02(0.16)$ & $0.17(0.75)$ & -1.03 \\
\hline I think that I will not master my daily live any more & $0.99(1.12)$ & $0.95(1.16)$ & $1.03(1.07)$ & -0.31 \\
\hline \multicolumn{5}{|l|}{ When I think about the group therapy in general... } \\
\hline $\begin{array}{l}\text { I am afraid that information from within the group will be spread outside of the } \\
\text { group }\end{array}$ & $0.63(0.87)$ & $0.54(0.78)$ & $0.77(0.97)$ & -1.11 \\
\hline I have learned that group therapy is not my thing & $1.01(1.30)$ & $1.10(1.30)$ & $0.90(1.32)$ & 0.63 \\
\hline $\begin{array}{l}\text { I have seen that I will get more problems in my life if I try to follow } \\
\text { recommendations from the group }\end{array}$ & $0.76(1.04)$ & $0.73(1.07)$ & $0.80(0.99)$ & -0.27 \\
\hline I am afraid that the group therapy will have negative consequences for my life & $0.23(0.54)$ & $0.29(0.60)$ & $0.13(0.43)$ & 1.30 \\
\hline
\end{tabular}


experience. There is also a trend ( $p 0,054,2$-tailed) for the item "When I think of the other participants of the group, I often felt like being forced to say something." which may indicate that males have some difficulties to express themselves in a group psychotherapy setting. Overall, there were no further differences between sexes, which is contrary to our expectations. Females and males alike have the same rate of negative experiences, be it because of the size of the group and the room, the content of discussions, the behavior of other patients, the behavior of the therapist, or anticipated long-term effects. This indicates that the biological sex is probably less important than individual gender-stereotypes of patients $[31,32]$. Another explanation could be that males who are mentally ill, who have been admitted in a psychosomatic hospital, and are in need of help behave different from others.

There are several limitations of this study. The results are based on self-reports. Since no information is provided on the present state of illness, this may cause confusion with non-group related factors and illness complaints. As there are not enough cases, we also could not test for differences in regard to diagnoses. The data originate from a special patient sample of inpatients so that results may deviate in other settings. We do not have information on what precisely was done in the treatment groups. We can only state that the therapists are well-trained in behavior therapy, supervised on a weekly basis by a senior behavior therapist, and have a long expertise.

One strength of the study is the systematic approach to study negative side effects by using a standardized questionnaire. Finally, to our knowledge this is the first study which investigates side effects of group cognitive behavior therapy in relation to gender. The study gives a first impression of negative side effects of group psychotherapy. It illustrates the need for further research in this area. Side effects should not be ignored in research and in particular in clinical practice. Research is needed in order to minimize burdens for patients.

\section{References}

1. Ogrodniczuk JS, Kealy D, Joyce AS, Abbass AA. Body talk: Sex differences in the influence of alexithymia on physical complaints among psychiatric outpatients. Psychiatry Res. 2018; 261: 168 -172. PubMed: https://pubmed.ncbi.nlm.nih.gov/29309955/

2. Seidler ZE, Rice SM, Ogrodniczuk JS, Oliffe JL, Dhillon HM. Engaging men in psychological treatment: a scoping review. Am J Mens Health. 2018; 12: 1882-1900.

PubMed: https://pubmed.ncbi.nlm.nih.gov/30103643/

3. Krause Girth C. Psychotherapie, Gesundheit und Geschlecht Argumente für eine geschlechtersensible und gesundheits för derliche Psychotherapie. Psychotherapie Forum. 2004; 12: 26-35.

4. Walton C, Coyle A, Lyons E. Death and football: An analysis of men's talk about emotions. Br J Soc Psychol. 2004; 43: 401-416.

PubMed: https://pubmed.ncbi.nlm.nih.gov/15479538/

5. Tenenbaum HR, Ford S, Alkhedairy B. Telling stories: Gender differences in peers'emotion talk and communication style. $\mathrm{Br} \mathrm{J}$ Dev Psychol. 2010; 29: 707-721.

PubMed: https://pubmed.ncbi.nlm.nih.gov/21199499/
6. Fischer AR., Good GE. Men and psychotherapy: An investigation of alexithymia, intimacy, and masculine gender roles. Psychotherapy. 1997; 34: 160-170.

7. Ogrodniczuk JS. Men, women, and their outcome in psychotherapy. Psychother Res. 2006; 16: 453-462.

8. Pattee D., Farber BA. Patients' experiences of self disclosure in psychotherapy: The effects of gender and gender role identification. Psychother Res. 2008; 18: 306-315.

PubMed: https://www.ncbi.nlm.nih.gov/pubmed/18815982

9. Grubbs KM, Cheney AM, Fortney JC, Edlund C, Han X, et al. The role of gender in moderating treatment outcome in collaborative care for anxiety. Psychiatr Serv. 2015; 66: 265-271.

PubMed: https://pubmed.ncbi.nlm.nih.gov/25727114/

10. Kvarstein EH, Nordviste O, Dragland L, Wilberg T. Outpatient psychody namic group therapy Outcomes related to personality disorder, severity, age and gender. Personal Ment Health. 2017; 11: 37-50. PubMed: https://pubmed.ncbi.nlm.nih.gov/27766761/

11. Staczan P, Schmuecker R, Koehler M, Berglar J, Crameri A, et al. Effects of sex and gender in ten types of psychotherapy. Psychother Res. 2017; 27: 74-88.

PubMed: https://pubmed.ncbi.nlm.nih.gov/26291131/

12. Haarmans M, McKenzie K, Kidd SA, Bentall RP. Gender role strain, core schemas, and psychotic experiences in ethnically diverse women: $A$ role for sex-and gender-based analysis in psychosis research? Clin Psychol Psychother. 2018; 25: 774-784.

PubMed: https://pubmed.ncbi.nlm.nih.gov/29978520/

13. Hannover B. Sozialpsychologie und Geschlecht: Die Entstehung von Geschlechtsunterschieden aus der Sicht der Selbstpsychologie. In G. Steins (Hrsg.), Handbuch Psychologie und Geschlechterforschung. Wiesbaden: VS Verlag für Sozialwissenschaften/Springer Fachmedien. 2010.

14. Schmid Mast M. Gender Differences and Similarities in Dominance Hierarchies in Same Gender Groups Based on Speaking Time. Sex Roles. 2001; 44: 537-556.

15. McHugh MC, Hambaugh J, Said S, Said H. Gender, Language and Power. In Chrisler JC, McCreary DR. (Eds.) Handbook of Gender Research in Psychology. Vol 1: Gender Research in General and Experimental Psychology. New York: Springer Science+Business Media, LLC. 2010.

16. Stengler K, Glaesmer H, Dietrich S. Gender and geschlechtsspezifische Aspekte in der psychiatrischen und psychotherapeutischen Forschung eine bibliometrischeAnalyse. Ztschr Psychiat Psychol Psychother. 2011; 59: 305-310.

17. Haupt ML, Linden M, Strauß B. Definition und Klassifikation von Psychotherapie Nebenwirkungen. In M. Linden, B. Strauß (Hrsg.) Risiken und Nebenwirkungen von Psychotherapie. Berlin: Medizinisch Wissenschaftliche Verlagsgesellschaft. 2013.

18. Linden M. How to define, find and classify side effects in psychotherapy: From unwanted events to adverse treatment reactions. Clin Psychol Psychother. 2013; 20: 286-296.

PubMed: https://www.ncbi.nlm.nih.gov/pubmed/22253218

19. Lieberei $B$, Linden M. Unerwünschte Effekte, Nebenwirkungen und Behandlungsfehler in der Psychotherapie. Zschr Evidenz, Fortbildung und Qualität im Gesundheitswesen. 2009; 102: 558-562.

20. Heins MJ, Knoop H, Prins JB, Stulemeijer M, Van der Meer JWM, et al. Possible Detrimental Effects of Cognitive Behaviour Therapy for Chronic Fatigue Syndrome. Psychother Psychosom. 2010; 79: 249-256. PubMed: https://www.ncbi.nlm.nih.gov/pubmed/20502065

21. Crawford MJ, Thana L, Farquharson L, Palmer L, Hancock E, et al Patient experience of negative effects of psychological treatment: 
results of a national survey. $\mathrm{Br} \mathrm{J}$ Psychiat. 2016; 208: 260-265. PubMed: https://pubmed.ncbi.nlm.nih.gov/26932486/

22. Hoffmann So, Rudolf G, Strauß B. Unerwünschte und schädliche Wirkungen von Psychotherapie. Psychotherapeut. 2008; 53: 4-16.

23. Strauß B, Mattke D. Nebenwirkungen und unerwünschte Wirkungen von Gruppentherapien. In Linden M., Strauß B. (Hrsg.), Risiken und Nebenwirkungen von Psychotherapie. Berlin: Medizinisch Wissenschaftliche Verlagsgesellschaft. 2013.

24. Schneibel R, Wilbertz G, Scholz C, Becker M, Brakemeier EL, et al Adverse events of group psychotherapy in the in-patient settingresults of a naturalistic trial. Acta Psychiatr Scand. 2017; 136: 247-258. PubMed: https://pubmed.ncbi.nlm.nih.gov/28561929/

25. Linden $M$, Walter $M$, Fritz $K$, Muschalla $B$. Unerwünschte Therapiewirkungen bei verhaltenstherapeutischer Gruppentherapie. Häufigkeit und Spektrum. Der Nervenarzt. 2015; 86: 1371-1382.

26. Flöge B, Fay $D$, Jöbges $M$, Linden $M$, Muschalla B. Nebenwirkungen von Ergotherapiegruppen. Fortschritte der Neurologie Psychiatrie. 2016; 84: 729-732
27. Frettlöh J, Kröner Herwig B. Einzel und Gruppentherapie in der Behandlung chronischer Schmerzen Gibt es Effektivitätsunterschiede? Zschr Klin Psychol. 1999; 28: 256-266.

28. Koch S, Geissner E, Hillert A. Berufliche Behandlungseffekte in der stationären Psychosomatik. Zschr Psychiat, Psychol. Psychother. 2007; 55: 97-109.

29. Yalom ID. Theorie und Praxis der Gruppenpsychotherapie. Stuttgart: Klett Cotta. 2007.

30. Turabian JL. Transference and countertransference are linked to placebo nocebo effects and they are an auxiliary resource of unparalleled value in general medicine: Recommendations for general practitioners. Arch Psychiatr Ment Health. 2020; 4: 001-006.

31. Huselid RF, Cooper ML. Gender Roles as Mediators in Sex Differences in Expressions of Pathology. J Abnormal Psychol. 1994; 103: 595-603. PubMed: https://pubmed.ncbi.nlm.nih.gov/7822560/

32. Schigl B. Psychotherapie und Gender. Konzepte. Forschung. Praxis. Wiesbaden: VS Verlag für Sozialwissenschaften/Springer Fachmedien. 2012. 